\title{
Is There a Gender Difference in Clinical Presentation of Renal Hyperparathyroidism and Outcome after Parathyroidectomy?
}

\author{
Claudia Bures Tatjana Skachko Eva M. Dobrindt Johann Pratschke \\ Deniz Uluk Martina T. Mogl \\ Department of Surgery, Campus Charité Mitte/Campus Virchow-Klinikum, Charité, Universitätsmedizin Berlin, \\ Corporate Member of Freie Universität Berlin, Humboldt-Universität zu Berlin, and Berlin Institute of Health, \\ Berlin, Germany
}

\section{Keywords}

Secondary hyperparathyroidism . Chronic kidney disease . Parathyroidectomy · Gender medicine · Cerebrovascular complication

\begin{abstract}
Introduction: Gender has been proven to influence the pathophysiology and treatment of numerous diseases, including kidney diseases and hormonal dysfunction like hyperparathyroidism. Thus, higher parathormone levels have been demonstrated in women with end-stage kidney disease, when compared to men. Objectives: We questioned whether female gender is associated with an increased risk for parathyroid nodular hyperplasia and necessary parathyroidectomy in dialysis patients and assessed demographics as well as outcome data for women and men undergoing parathyroidectomy for renal hyperparathyroidism. Patients and Methods: One hundred and thirty patients (men $=75$, female $=55$ ) with end-stage renal disease on chronic dialysis and advanced secondary hyperparathyroidism who underwent parathyroidectomy between 2008 and 2014 at our center were analyzed retrospectively. Perioperative characteristics and short-term outcome were evaluated with respect to biological gender. Results: No differences could be demonstrated for patient demography, comorbidities and the perioperative course between males and females. Only preoperative calcium levels were lower in female than in male patients $(2.3 \pm 0.19$ vs. $2.3 \pm 0.26, p=0.04)$. There were more women, however, with cerebrovascular complications dur-
\end{abstract}

ing follow-up $(p=0.04)$. There was no postoperative mortality, and all complications and comorbidities with exception of cerebrovascular diseases were equally distributed between female and male patients. Conclusion: Overall, we could not demonstrate many significant differences between male and female patients with end-stage renal diseases, chronic dialysis and operated secondary hyperparathyroidism. Only preoperative electrolyte levels were higher in male than in female patients, and cerebrovascular complications developed more often in females than in males during long-term follow-up.

(c) 2020 S. Karger AG, Basel

\section{Introduction}

Secondary hyperparathyroidism (sHPT) is highly prevalent among patients with end-stage renal disease (ESRD) [1-3] and is associated with progressive bone disease, susceptibility to bone fractures, and vascular calcification as well as myocardial infarction and reduced life expectancy [4-7]. Since gender differences have been found in patients with chronic kidney disease (CKD) we questioned whether men and women with renal sHPT may also present with different symptoms, variable pathophysiology and disease tolerance, as well as different response to therapy.

D.U. and M.T.M. contributed equally to this work. 
Physiological differences in the kidneys of men and women include both morphological and physiological aspects [8-10]. Studies have shown that men have larger and wider kidneys compared to women [9], although the overall kidney volume seems to be equivalent [10]. Women have a higher renovascular resistance, a lower absolute glomerular filtration rate and lower renal plasma flow compared to men [11]. At a molecular level, men and women exhibit significant differences. Kidneys of men exhibit larger mitochondria, more lysosomes and more abundant ribosomes in the proximal tubular cells than the kidneys of women [12]. At a functional level, sex differences have been reported in the renin-angiotensin system and in the regulation of blood pressure [13, 14]. Additionally, it has been shown that sex hormones play a significant role: estrogen increases synthesis of angiotensinogen and decreases the synthesis of renin and angiotensin-converting enzyme. Testosterone, on the other hand, is associated with an increased renin release in small animal models $[15,16]$. As such, sex has been interpreted as an important factor influencing both kidney function and the progression of kidney disease [17]: female gender is at risk for developing CKD [18-20] and is more prevalent in women than in men [21]. Additionally, Indridason et al. [22] described gender-specific differences in primary CKD and with patients on chronic dialysis: thus, females exhibited a higher rate of diabetes mellitus, and their dialysis dose was higher than that of men.

Interestingly, female gender favors parathyroid cell proliferation, and parathyroid glands of uremic women are more prone to develop nodular hyperplasia compared to their male counterparts [23-25]. This effect of gender-specific parathyroid growth and parathyroid function could be explained by different factors, including the different serum estrogen levels in men and women, since estrogen receptors have been shown to be expressed on parathyroid cells [26]. Even though estradiol levels are normal in the majority of women undergoing dialysis $[27,28]$, amenorrhea or anovulatory periods are common in these patients and long periods of unopposed estrogen exposure may lead to parathyroid stimulation $[26,29,30]$. Additionally, it was shown that women do suffer from a larger phosphate burden than men $[24,25]$ and women undergoing dialysis presented with higher parathormone (PTH) serum levels than men [3133].

Altogether women inherit a higher risk for developing primary hyperparathyroidism [34, 35], and in uremic women an increased severity of sHPT has been found in comparison to men [22, 24, 31, 33, 36, 37]. Therefore, more female patients undergo parathyroidectomy (PTX) $[32,33,37,38]$, when compared to men.

Female patients in general exhibit a higher susceptibility to bone fractures and a higher risk for ESRD [39].
Additional to this, the overall incidence of hip fractures in patients with chronic renal dialysis is about fourfold to the normal population [39] and increases with age [40-44]. When compared to men, women with sHPT further demonstrate more profound downregulation of bone mineral metabolism before PTX $[19,45]$. The abnormal ovarian function, frequently observed in uremic women $[27,28]$, may additionally predispose for increased bone mineral and total bone resorption. These factors may explain, why Isaksson et al. [46] could demonstrate that sPTX reduces the risk of hip fractures especially in female patients with sHPT. In contrast to this, Rudser et al. [47] found no sex differences in bone fracture risk after PTX. Ishani et al. [48] even reported that PTX had no effect on bone fracture rate in patients on chronic dialysis, after PTX. They did not compare gender effects, however.

In this study we analyze whether gender plays an important role in patients with renal sHPT because of terminal kidney insufficiency and chronic dialysis and we compared patient history, operative procedures and results of early as well as long-term postoperative followup.

\section{Materials and Methods}

All patients undergoing PTX due to sHPT at our center, between 2008 and 2014, have been included into our database prospectively and were analyzed retrospectively. All patients of our cohort had renal HPT due to ESRD with dialysis and were listed for renal transplantation. Patients were analyzed for demographic parameters like age, body mass index and sex as well as diseasespecific information, comorbidities and beginning of dialysis. Prospective data collection and retrospective analysis were performed in accordance with the Declaration of Helsinki and approved by the local Ethics Committee.

Perioperative laboratory values were recorded including creatinine, calcium, intact PTH and hemoglobin levels. Operationspecific data such as procedure and operation time were also included.

Intra- and early postoperative procedures, morbidity and mortality were registered, including complications like bleeding, vocal cord palsy, length of hospital stay and persistence of hyperparathyroidism. In long-term follow-up, overall survival and cardiovascular as well as cerebrovascular events were assessed.

The existing data and the added information were extracted into an Excel datasheet (Microsoft Office Excel 2019, Microsoft Corporation, Redmond, WA, USA). The statistical analyses and the created diagrams were made with Statistical Package for Social Sciences software (SPSS ${ }^{\circledR}$ 25.0, Chicago, IL, USA). Patients were analyzed with respect to biological gender. Descriptive values are given as median or mean, SD and range. If parameters for both groups were normally distributed, a Student $t$ test could be performed for probable significance. Quantitative variables with nonparametric distribution were checked by the Mann-Whitney U test for significant differences. Further correlations or relations between categorical data were calculated by the $\chi^{2}$ test and Fisher's exact test. The significance level was set at $p<0.05$. 
Table 1. Demographic parameters of patients $(n, \%)$ undergoing parathyroidectomy for secondary hyperparathyroidism $(n=130)$

\begin{tabular}{lc}
\hline Sex ${ }^{1}$ & \\
Male & $75(58)$ \\
Female & $55(42)$ \\
Age, years ${ }^{1}$ & \\
Mean & $50 \pm 14$ \\
Range & $12-82$ \\
ASA >III & $110(85)$ \\
aHT yes & $128(98)$ \\
Diabetes yes & $31(24)$ \\
Adipositas yes & $15(12)$ \\
CHD yes & $35(27)$ \\
Dialysis dependency yes & $130(100)$ \\
Age at beginning of dialysis, years & \\
Mean & $46 \pm 14.8$ \\
Range & $12-78$ \\
Duration of time between dialysis and PTX, years \\
Mean \\
Range & $4.7 \pm 3.9$ \\
Dialysis intervals 3 times/week & $0-27$ \\
Kidney disease & $130(100)$ \\
Glomerulonephritis & \\
Tubulointerstitial & $35(27)$ \\
Hypertensive & $19(15)$ \\
Diabetic & $20(15)$ \\
Polycystic & $18(14)$ \\
Atrophic & $15(12)$ \\
Alport syndrome & $4(3)$ \\
Amyloidosis & $2(2)$ \\
Other & $1(1)$ \\
Unknown & $13(10)$ \\
Operative procedure & $3(2)$ \\
Total PTX & \\
Subtotal PTX & $29(22)$ \\
Selective PTX & $88(68)$ \\
Duration of surgery, min & $13(10)$ \\
Mean & \\
Range & $31-39$ \\
Postoperative complication yes & $28(22)$ \\
Myocardial infarction & $17(13)$ \\
Apoplexy & \\
Bleeding & \\
Hospital stay, days & \\
Mean & \\
Range & \\
\hline & \\
\hline
\end{tabular}

${ }^{1}$ Matched parameters. Values as numbers and percentages or means \pm SD. ASA, American Society of Anesthesiologists; aHT, arterial hypertension; CHD, coronary heart diseases; PTX, parathyroidectomy.

\section{Results}

In total 130 patients with PTX for sHPT could be included retrospectively. All patients had ESRD and had been on dialysis for approximately 4.7 years $( \pm 3.9$, range $0-27)$, while being listed for renal transplantation. There was a slight majority of male patients $(58 \%, n=75)$. For all patients in this cohort, the age distribution ranged from 12 to 82 years with a mean of $50 \pm 14$ years. Nearly all patients were classified according to the American Society of Anesthesiologists in group III or higher when the patient's specific risk factors were considered before surgery. Comorbidities such as arterial hypertension occurred in nearly all patients $(98 \%, n=128)$. Diabetes mellitus has been verified in 31 patients (24\%), and almost $15(12 \%)$ patients were classified as obese according to body mass index $\geq 30$. Thirty-five (27\%) patients were recorded with coronary heart disease. All patients were on dialysis due to ESRD, and dialysis was performed 3 times per week. The mean age at the beginning of dialyses for this cohort was $46 \pm 15$ years. The majority of patients was on dialysis due to glomerulonephritis $(n=35,27 \%)$, tubulointerstitial kidney damage $(n=19,15 \%)$, hypertensive kidney disease $(n=20,15 \%)$, diabetic nephropathy $(n=18,14 \%)$ or polycystic renal disease $(n=15,12 \%$; Table 1).

Most patients underwent subtotal PTX ( $n=88,68 \%)$. Total PTX was performed in 29 cases $(22 \%)$ including 5 patients with autotransplantation of parathyroid tissue into the sternocleidomastoid or forearm muscle. Selective PTX was performed in 13 cases (10\%) only, and mainly for re-operation of persisting hyperparathyroidism. The mean duration of surgery was $131 \pm 39$ min and ranged from 61 to $237 \mathrm{~min}$. The mean hospital stay was $6 \pm 5$ days (1-39 days), and postoperative complications occurred in 28 patients $(22 \%)$. The majority of severe complications in our patients were myocardial infarction in 16 patients (13\%), developing mainly during long-term follow-up. One patient demonstrated paroxysmal atrial fibrillation immediately postoperatively, and $8(6 \%)$ patients were recorded with cerebrovascular events during long-term follow-up. Postoperative bleeding with need for surgical revision was seen in 3 cases (2\%). None of the patients died during hospital stay, nor up to 30 days postoperatively. There was no statistically significant difference in patient history or perioperative complications between female and male patients (Table 2).

Also, comorbidities like arterial hypertension, diabetes mellitus, obesity and coronary heart disease were distributed similarly between the groups. Male patients showed a slight tendency to be younger at the onset of dialysis dependence with no statistical difference $(44 \pm 14$ vs. $49 \pm 16$ years, $p=0.08$; Fig. 1 ). The time between onset of dialysis and PTX was similar with $4.5 \pm 3.5$ for male and $4.9 \pm 4.4$ years for female patients ( $p=0.58$; Fig. 2 ).

Distribution of kidney diseases showed a tendency for more glomerulonephritis in male patients $(31 \%$ vs. female $22 \%$ ), while polycystic kidney disease seems to occur twice as often in female patients ( $8 \%$ male vs. $16 \%$ female) without significant differences overall.

Operative procedures were not statistically different for patients in both groups (Table 2), nor was length of 
Table 2. Demographic parameters for male and female patients undergoing parathyroidectomy for secondary hyperparathyroidism $(n=130)$

\begin{tabular}{|c|c|c|c|}
\hline & $\begin{array}{l}\text { Male } \\
(n=75)\end{array}$ & $\begin{array}{l}\text { Female } \\
(n=55)\end{array}$ & $\begin{array}{l}p \\
\text { value }\end{array}$ \\
\hline \multicolumn{4}{|l|}{ Age, years ${ }^{1}$} \\
\hline Mean & $49 \pm 13$ & $53 \pm 15$ & 0.11 \\
\hline Range & $26-75$ & $12-82$ & \\
\hline ASA >III & $63(85)$ & $47(90)$ & 0.61 \\
\hline aHT yes & $74(99)$ & $54(98)$ & 0.39 \\
\hline Diabetes yes & $17(23)$ & $14(26)$ & 0.66 \\
\hline Adipositas yes & $8(11)$ & $7(13)$ & 0.68 \\
\hline CHD yes & $19(25)$ & $16(30)$ & 0.58 \\
\hline \multicolumn{3}{|l|}{ Age at dialysis dependency, years } & 0.08 \\
\hline Mean & $44 \pm 14$ & $48.8 \pm 15.6$ & \\
\hline Range & $18-73$ & $12-78$ & \\
\hline \multicolumn{4}{|c|}{ Dialysis-depending time till operation, years } \\
\hline Mean & $4.5 \pm 3.5$ & $4.9 \pm 4.4$ & 0.58 \\
\hline Range & $0-18$ & $0-27$ & \\
\hline \multicolumn{4}{|l|}{ Kidney disease } \\
\hline Glomerulonephritis & $23(31)$ & $12(22)$ & 0.38 \\
\hline Tubulointerstitial & $12(16)$ & $7(13)$ & \\
\hline Hypertensive & $10(13)$ & $10(18)$ & \\
\hline Diabetic & $9(12)$ & $9(16)$ & \\
\hline Polycystic & $6(8)$ & $9(16)$ & \\
\hline Atrophic & $3(4)$ & $1(2)$ & \\
\hline Alport syndrome & $2(3)$ & 0 & \\
\hline Amyloidosis & 0 & $1(2)$ & \\
\hline Other & $7(9)$ & $6(11)$ & \\
\hline Unknown & $3(4)$ & 0 & \\
\hline Treatment with cinacalcet yes & $33(44)$ & $19(35)$ & 0.27 \\
\hline \multicolumn{4}{|l|}{ Operative procedure } \\
\hline Total PTX & $14(19)$ & $15(27)$ & 0.44 \\
\hline Subtotal PTX & $54(72)$ & $34(62)$ & \\
\hline Selective PTX & $7(9)$ & $6(11)$ & \\
\hline \multicolumn{4}{|l|}{ Duration of surgery, min } \\
\hline Mean & $131 \pm 37$ & $131 \pm 42$ & \\
\hline Range & $61-237$ & $67-236$ & 0.98 \\
\hline Postoperative complication yes & $14(19)$ & $14(25)$ & 0.35 \\
\hline Myocardial infarction & $9(12)$ & $7(13)$ & 0.83 \\
\hline Apoplexy & $2(3)$ & $6(12)$ & 0.04 \\
\hline Bleeding & 0 & 0 & \\
\hline \multicolumn{4}{|l|}{ Hospital stay, days } \\
\hline Mean & $7 \pm 5$ & $6 \pm 5$ & 0.91 \\
\hline Range & $1-28$ & $1-39$ & \\
\hline \multicolumn{4}{|c|}{ Potassium level preoperative, $\mathrm{mmol} / \mathrm{L}$} \\
\hline Mean & $5.0 \pm 0.7$ & $4.7 \pm 0.85$ & 0.05 \\
\hline Range & $3.4-7.0$ & $3.1-7.3$ & \\
\hline \multicolumn{4}{|l|}{$\begin{array}{l}\text { Parathyroid hormone level } \\
\text { preoperative, ng/L }\end{array}$} \\
\hline Mean & $800 \pm 489$ & $653 \pm 425$ & 0.79 \\
\hline Range & $3-2,085$ & $112-2,164$ & \\
\hline \multicolumn{4}{|l|}{ Calcium level preoperative, $\mathrm{mmol} / \mathrm{L}$} \\
\hline Mean & $2.3 \pm 0.19$ & $2.3 \pm 0.26$ & 0.04 \\
\hline Range & $1.7-2.7$ & $1.21-2.91$ & \\
\hline \multicolumn{4}{|c|}{ Hemoglobin level preoperative, mg/dL } \\
\hline Mean & $11.9 \pm 1.9$ & $11.6 \pm 1.95$ & 0.29 \\
\hline Range & $6.3-16.5$ & $5.7-16.1$ & \\
\hline \multicolumn{4}{|c|}{ Potassium level postoperative, $\mathrm{mmol} / \mathrm{L}$} \\
\hline Mean & $4.7 \pm 0.63$ & $4.7 \pm 0.64$ & 0.66 \\
\hline Range & $3.6-6.1$ & $3.1-6.2$ & \\
\hline \multicolumn{4}{|c|}{ Parathyroid hormone level postoperative, ng/L } \\
\hline Mean & $44 \pm 83$ & $41 \pm 94$ & 0.09 \\
\hline Range & $3-440$ & $3-416$ & \\
\hline \multicolumn{4}{|c|}{ Hemoglobin level postoperative, g/dL } \\
\hline Mean & $11.1 \pm 1.4$ & $11.2 \pm 1.65$ & 0.82 \\
\hline Range & $8.5-14.5$ & $8.3-15.9$ & \\
\hline Hyperkalemia postoperative yes & $11(15)$ & $7(14)$ & 0.82 \\
\hline
\end{tabular}

${ }^{1}$ Matched parameters. Values as numbers and percentages or means \pm SD. ASA, American Society of Anesthesiologists; aHT, arterial hypertension; CHD, coronary heart diseases; PTX, parathyroidectomy.

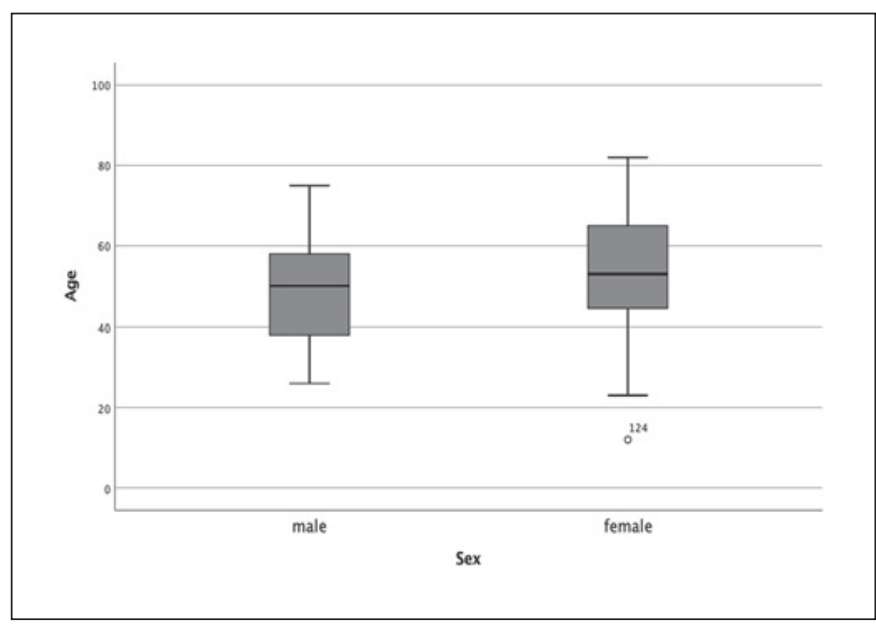

Fig. 1. Boxplot showing distribution of age at beginning of dialysis for female and male patients with no significant difference (male patients $44 \pm 14$ years vs. female patients $49 \pm 16$ years, $p=0.08$ ).

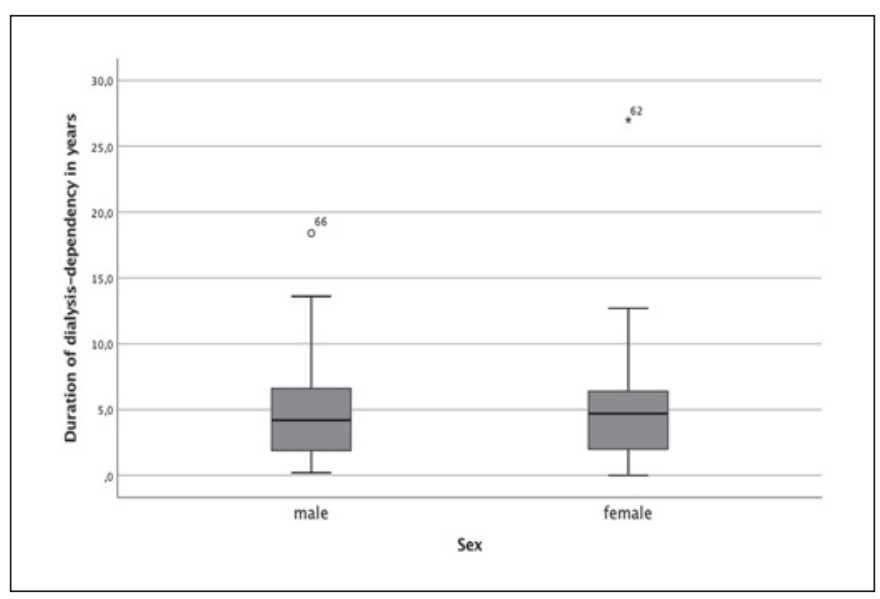

Fig. 2. Boxplot displaying duration of dialysis until parathyroidectomy for female and male patients without any significant difference $(4.5 \pm 3.5$ years for male vs. $4.9 \pm 4.4$ years for female patients, $p=0.58)$.

hospital stay $(p=0.91)$. Postoperative complications were different between the groups, however. Female patients were more likely to develop cerebrovascular complications like central strokes during long-term follow-up. Six of 8 events occurred in female patients $(p=0.04)$. All patients have been monitored after PTX for detection of cardiac arrhythmias with no significant differences (1 male patient). Myocardial infarction was detected equally in both groups (male 9 [12\%] vs. female 7 [13\%], $p=0.83$ ).

Male patients displayed higher serum potassium levels $(5.0 \pm 0.7 \mathrm{mmol} / \mathrm{L}$ vs. female $4.7 \pm 0.85 \mathrm{mmol} / \mathrm{L}, p=0.05)$, preoperatively. After surgery, serum potassium levels did not show any differences for both sexes $(4.7 \pm 0.6 \mathrm{mmol} / \mathrm{L}$ vs. female $4.7 \pm 0.6 \mathrm{mmol} / \mathrm{L}, p=0.05)$. Hyperkalemia was equally distributed in both genders (11 [15\%] vs. female $7[14 \%], p=0.82)$. PTH decreased or normalized in both 
groups without any statistically significant differences between sexes $(p=0.09)$. Preoperative serum calcium levels of female patients were significantly higher $(2.3 \pm 0.19$ $\mathrm{mmol} / \mathrm{L}$ vs. female $2.3 \pm 0.26 \mathrm{mmol} / \mathrm{L}, p=0.04)$. There was no difference in hemoglobin levels, neither pre- nor postoperatively, between both groups (Table 2).

\section{Discussion/Conclusion}

Gender has been suggested to be an important factor, when kidney function and progression of kidney disease are investigated $[17,21]$. Although the causes of renal failure were different between the 2 groups in our cohort, there were no gender differences in age, comorbidities and time of dialysis before PTX. Our results differ from international studies: Indridason et al. [22] showed that among dialysis patients more women were diagnosed with sHPT than men. Our group may be biased for listing to transplantation. Biological sex influences the pathogenesis of numerous diseases, including metabolic disorders such as diabetes [49]. Diabetes is the most common cause of ESRD in industrialized countries [50,51], and its prevalence tends to increase over time. In our cohort, no significant difference could be observed concerning the number of patients with diabetes mellitus. Furthermore, review of the recent literature [18-20,45] shows that women tend to have shorter time on dialysis before PTX than men. This is not reflected in our patients, where we could not see any difference between male and female patients concerning time on dialysis before PTX. This may be explained by the fact that our patients were generally operated on early: the mean time of dialysis before surgery was $4.7 \pm 3.9$ years, which is half the time stated in the literature [45]. But early surgical intervention for renal hyperparathyroidism in CKD patients may prevent metabolic and bone-related complications. Comparing perioperative laboratory parameters, only calcium values showed a significant difference between sexes. $40 \%$ of our patients, however, had been treated with cinacalcet preoperatively, which lowers calcium levels. Overall, it is well known that women have lower hemoglobin and hematocrit levels than men [21]. Anemia is a common problem in patients with ESRD, particularly when they are on chronic dialysis. Factors that may be responsible for anemia in CKD are blood loss, shortened red cell life span, vitamin deficiencies, erythropoietin deficiency, iron deficiency, infection and inflammation. Among these, erythropoietin deficiency is considered as the most important cause [52]. Additionally, sHPT leads to reduced response to the erythropoietin-stimulating agent [53] and both can be attributed to decreased red blood cell production. Furthermore, calcitriol deficiency and parathyroid overproduction in patients with sHPT may inhibit erythropoio- genesis because of secondary bone marrow fibrosis and may reduce red blood cell survival, both aggravating renal anemia [54]. Previous studies in hemodialysis patients revealed a significant relationship between erythropoietinstimulating agent hyporesponsiveness and higher intact PTH level and the inverse relationship between PTH and hemoglobin level [55-57]. In our center most patients were treated with erythropoietin to treat anemia, and we could not calculate any difference in hemoglobin levels between both sexes.

While overall postoperative complications were low, we saw significantly more cerebrovascular events in female patients during follow-up. This result has not yet been documented in the literature for SHPT and needs to be confirmed in further trials. Interestingly, although some studies do report a higher incidence of stroke in females compared to male patients, in general [58], it was attributed to differences in age, medical history and other relevant risk factors, but not to gender differences, as it occurred in our patients [59].

This study has several limitations. It is a retrospective and monocentric study with a limited number of patients. Furthermore, we do not have any information about bone mineral density in our patients and also no information on sex-specific hormones or information about menstruation or menopause of our female patients.

In conclusion, we assessed the impact of gender on history and peri- as well as postoperative outcome in patients with renal sHPT. Clinical and biochemical history only showed minor differences between both sexes with higher preoperative calcium levels in men. Operative procedures and early postoperative complications were not different. But in long-term follow-up women suffered from significantly more cerebrovascular complications than men. This latter finding is new and unexpected but has to be confirmed in further studies.

\section{Acknowledgment}

We want to acknowledge all patients involved with direct patient care, especially from the kidney transplant office, namely Esther Wichmann, Petra Hecker and Birgit Kulawick. Additionally, we want to thank Michael Hippler-Benscheidt for support with data acquisition and analysis.

\section{Statement of Ethics}

This is a retrospective noninterventional study. All procedures performed were in accordance with the ethical standards of the Institutional Research Committee and with the 1964 Helsinki Declaration and its later amendments or comparable ethical standards. An ethical approval for processing and publication of the data has been obtained by the institutional Ethics Committee (EA4/086/19); no written informed consent was necessary. 


\section{Disclosure Statement}

The authors declare that they have no conflict of interest.

\section{Funding Sources}

All authors are hospital employees, no funding was available.

\section{Author Contributions}

C.B., D.U. and M.T.M. contributed to the study conception and design, analysis, interpretation of data and writing of the manuscript. D.U., T.S., E.M.D. and M.T.M. participated in the acquisition and analysis of data. J.P. contributed to the analysis and interpretation of data, the study conception and critical review of the manuscript.

\section{References}

1 National Kidney Foundation. K/DOQI clinical practice guidelines for bone metabolism and disease in chronic kidney disease. Am J Kidney Dis. 2003 Oct;42(4 Suppl 3):S1-201.

2 Goodman WG, Quarles LD. Development and progression of secondary hyperparathyroidism in chronic kidney disease: lessons from molecular genetics. Kidney Int. 2008 Aug;74(3):276-88.

3 Sherrard DJ, Hercz G, Pei Y, Maloney NA, Greenwood C, Manuel A, et al. The spectrum of bone disease in end-stage renal failure-an evolving disorder. Kidney Int. 1993 Feb; 43(2):436-42.

4 Danese MD, Kim J, Doan QV, Dylan M, Griffiths R, Chertow GM. PTH and the risks for hip, vertebral, and pelvic fractures among patients on dialysis. Am J Kidney Dis. 2006 Jan;47(1):149-56

5 Goodman WG, Goldin J, Kuizon BD, Yoon C, Gales B, Sider D, et al. Coronary-artery calcification in young adults with end-stage renal disease who are undergoing dialysis. N Engl Med. 2000 May;342(20):1478-83.

6 Jadoul M, Albert JM, Akiba T, Akizawa T, Arab L, Bragg-Gresham JL, et al. Incidence and risk factors for hip or other bone fractures among hemodialysis patients in the Dialysis Outcomes and Practice Patterns Study. Kidney Int. 2006 Oct;70(7):1358-66.

7 Raggi P, Boulay A, Chasan-Taber S, Amin N, Dillon M, Burke SK, et al. Cardiac calcification in adult hemodialysis patients. A link between end-stage renal disease and cardiovascular disease? J Am Coll Cardiol. 2002 Feb; 39(4):695-701

8 Sabolić I, Asif AR, Budach WE, Wanke C Bahn A, Burckhardt G. Gender differences in kidney function. Pflugers Arch. 2007 Dec; 455(3):397-429.

9 Miletić D, Fuckar Z, Sustić A, Mozetic V, Stimac D, Zauhar G. Sonographic measurement of absolute and relative renal length in adults. J Clin Ultrasound. 1998 May;26(4):185-9.

10 Jovanović D, Gasic B, Pavlovic S, Naumovic R. Correlation of kidney size with kidney function and anthropometric parameters in healthy subjects and patients with chronic kidney diseases. Ren Fail. 2013 Jul;35(6):896900.

11 Munger K, Baylis C. Sex differences in renal hemodynamics in rats. Am J Physiol. 1988 Feb;254(2 Pt 2):F223-31.

12 Hutchens MP, Dunlap J, Hurn PD, Jarnberg PO. Renal ischemia: does sex matter? Anesth Analg. 2008 Jul;107(1):239-49.
13 Chen K, Bi J, Su Y, Chappell MC, Rose JC. Sex-Specific Changes in Renal AngiotensinConverting Enzyme and Angiotensin-Converting Enzyme 2 Gene Expression and Enzyme Activity at Birth and Over the First Year of Life. Reprod Sci. 2016 Feb;23(2):200-10.

14 Hilliard LM, Sampson AK, Brown RD, Denton KM. The "his and hers" of the renin-angiotensin system. Curr Hypertens Rep. 2013 Feb;15(1):71-9.

15 Quan A, Chakravarty S, Chen JK, Chen JC, Loleh S, Saini N, et al. Androgens augment proximal tubule transport. Am J Physiol Renal Physiol. 2004 Sep;287(3):F452-9.

16 Quigley R. Androgens stimulate proximal tubule transport. Gend Med. 2008;5(Suppl A):S114-20.

17 Silbiger S, Neugarten J. Gender and human chronic renal disease. Gend Med. 2008; 5(Suppl A):S3-10.

18 Pazianas M, Phillips ME, MacRae KD, Eastwood JB. Identification of risk factors for radiographic hyperparathyroidism in 422 patients with end-stage renal disease: development of a clinical predictive index. Nephrol Dial Transplant. 1992;7(11):1098-105.

19 Luisetto G, Bertoli M. Sexual influence on bone metabolism in uremic patients on regular dialytic treatment. Nephron. 1994;67(2): $150-7$.

20 Taal MW, Masud T, Green D, Cassidy MJ. Risk factors for reduced bone density in haemodialysis patients. Nephrol Dial Transplant. 1999 Aug;14(8):1922-8.

21 Cobo G, Hecking M, Port FK, Exner I, Lindholm B, Stenvinkel P, et al. Sex and gender differences in chronic kidney disease: progression to end-stage renal disease and haemodialysis. Clin Sci (Lond). 2016 Jul;130(14): 1147-63.

22 Indridason OS, Pieper CF, Quarles LD. Predictors of short-term changes in serum intact parathyroid hormone levels in hemodialysis patients: role of phosphorus, calcium, and gender. J Clin Endocrinol Metab. 1998 Nov; 83(11):3860-6.

23 Almaden Y, Felsenfeld AJ, Rodriguez M, Cañadillas S, Luque F, Bas A, et al. Proliferation in hyperplastic human and normal rat parathyroid glands: role of phosphate, calcitriol, and gender. Kidney Int. 2003 Dec;64(6): 2311-7.

24 Lomonte C, Cazzato F, Casucci F, Chimienti D, Bruno A, Cocola S, et al. Female hemodialysis patients have an increased risk of nodular hyperplasia of parathyroid glands. J Nephrol. 2005 Jan-Feb;18(1):92-5.
25 Basile C, Lomonte C, Vernaglione L, Casucci F, Chimienti D, Bruno A, et al. A high body mass index and female gender are associated with an increased risk of nodular hyperplasia of parathyroid glands in chronic uraemia. Nephrol Dial Transplant. 2006 Apr;21(4): 968-74.

26 Prince RL. Counterpoint: estrogen effects on calcitropic hormones and calcium homeostasis. Endocr Rev. 1994 Jun;15(3):301-9.

27 Zingraff J, Jungers P, Pélissier C, Nahoul K, Feinstein MC, Scholler R. Pituitary and ovarian dysfunctions in women on haemodialysis. Nephron. 1982;30(2):149-53.

28 Lim VS, Henriquez C, Sievertsen G, Frohman LA. Ovarian function in chronic renal failure: evidence suggesting hypothalamic anovulation. Ann Intern Med. 1980 Jul;93(1):21-7.

29 Naveh-Many T, Almogi G, Livni N, Silver J. Estrogen receptors and biologic response in rat parathyroid tissue and C cells. J Clin Invest. 1992 Dec;90(6):2434-8.

30 Cosman F, Nieves J, Horton J, Shen V, Lindsay R. Effects of estrogen on response to edetic acid infusion in postmenopausal osteoporotic women. J Clin Endocrinol Metab. 1994 Apr;78(4):939-43.

31 Fan SL, Chan A, Raftery MJ, Yaqoob MM. Race and sex: predictors of the severity of hyperparathyroidism in peritoneal dialysis patients. Nephrology (Carlton). 2006 Feb;11(1): 15-20.

32 Kestenbaum B, Seliger SL, Gillen DL, Wasse H, Young B, Sherrard DJ, et al. Parathyroidectomy rates among United States dialysis patients: 1990-1999. Kidney Int. 2004 Jan;65(1): 282-8.

33 Malberti F, Marcelli D, Conte F, Limido A, Spotti D, Locatelli F. Parathyroidectomy in patients on renal replacement therapy: an epidemiologic study. J Am Soc Nephrol. 2001 Jun;12(6):1242-8

34 Miller BS, Dimick J, Wainess R, Burney RE. Age- and sex-related incidence of surgically treated primary hyperparathyroidism. World J Surg. 2008 May;32(5):795-9.

35 Melton LJ 3rd. The epidemiology of primary hyperparathyroidism in North America. J Bone Miner Res. 2002 Nov;17(Suppl 2):N12-

36 Gupta A, Kallenbach LR, Zasuwa G, Divine GW. Race is a major determinant of secondary hyperparathyroidism in uremic patients. J Am Soc Nephrol. 2000 Feb;11(2):330-4. 
37 Foley RN, Li S, Liu J, Gilbertson DT, Chen SC, Collins AJ. The fall and rise of parathyroidectomy in U.S. hemodialysis patients, 1992 to 2002. J Am Soc Nephrol. 2005 Jan;16(1):2108.

38 Wermers RA, Khosla S, Atkinson EJ, Hodgson SF, O'Fallon WM, Melton LJ 3rd. The rise and fall of primary hyperparathyroidism: a population-based study in Rochester, Minnesota, 1965-1992. Ann Intern Med. 1997 Mar; 126(6):433-40.

39 Alem AM, Sherrard DJ, Gillen DL, Weiss NS, Beresford SA, Heckbert SR, et al. Increased risk of hip fracture among patients with endstage renal disease. Kidney Int. 2000 Jul;58(1): 396-9.

40 Jones G, Nguyen T, Sambrook PN, Kelly PJ, Gilbert C, Eisman JA. Symptomatic fracture incidence in elderly men and women: the Dubbo Osteoporosis Epidemiology Study (DOES). Osteoporos Int. 1994 Sep;4(5):27782.

41 Jacobsen SJ, Goldberg J, Miles TP, Brody JA, Stiers W, Rimm AA. Hip fracture incidence among the old and very old: a populationbased study of 745,435 cases. Am J Public Health. 1990 Jul;80(7):871-3.

42 Kelsey JL, Browner WS, Seeley DG, Nevitt MC, Cummings SR; The Study of Osteoporotic Fractures Research Group. Risk factors for fractures of the distal forearm and proximal humerus [Erratum in: Am J Epidemiol 1992 May 15;135] [10]. Am J Epidemiol. 1992 Mar;135(5):477-89.

43 Donaldson LJ, Cook A, Thomson RG. Incidence of fractures in a geographically defined population. J Epidemiol Community Health. 1990 Sep;44(3):241-5.
44 Cummings SR, Kelsey JL, Nevitt MC, O’Dowd KJ. Epidemiology of osteoporosis and osteoporotic fractures. Epidemiol Rev. 1985;7(1): 178-208.

45 Cheng SP, Yang TL, Lee JJ, Chen HH, Wu CJ, Liu TP, et al. Gender differences among patients with secondary hyperparathyroidism undergoing parathyroidectomy. J Surg Res. 2011 Jun;168(1):82-7.

46 Isaksson E, Ivarsson K, Akaberi S, Muth A, Sterner G, Karl-Göran P, et al. The Effect of Parathyroidectomy on Risk of Hip Fracture in Secondary Hyperparathyroidism. World J Surg. 2017 Sep;41(9):2304-11.

47 Rudser KD, de Boer IH, Dooley A, Young B, Kestenbaum B. Fracture risk after parathyroidectomy among chronic hemodialysis patients. J Am Soc Nephrol. 2007 Aug;18(8): 2401-7.

48 Ishani A, Liu J, Wetmore JB, Lowe KA, Do T, Bradbury BD, et al. Clinical outcomes after parathyroidectomy in a nationwide cohort of patients on hemodialysis. Clin J Am Soc Nephrol. 2015 Jan;10(1):90-7.

49 Campesi I, Franconi F, Seghieri G, Meloni M. Sex-gender-related therapeutic approaches for cardiovascular complications associated with diabetes. Pharmacol Res. 2017 May;119: 195-207.

50 Villar E, Zaoui P. [Diabetes and chronic kidney disease: lessons from renal epidemiology]. Nephrol Ther. 2010 Dec;6(7):585-90.

51 Kabbali N, Mikou S, El Pardiya NT, El Bardai G, Arrayhani M, Houssaini TS. [Profile of diabetic in chronic hemodialysis: a multicenter study in Morocco]. Pan Afr Med J. 2014 Feb; $17: 125$.
52 Nurko S. Anemia in chronic kidney disease: causes, diagnosis, treatment. Cleve Clin J Med. 2006 Mar;73(3):289-97.

53 Amnuay K, Srisawat N, Wudhikarn K, Assanasen T, Polprasert C. Factors associated with erythropoiesis-stimulating agent hyporesponsiveness anemia in chronic kidney disease patients. Hematol Rep. 2019 Sep;11(3): 8183.

54 Drüeke TB, Eckardt KU. Role of secondary hyperparathyroidism in erythropoietin resistance of chronic renal failure patients. Nephrol Dial Transplant. 2002;17(17 Suppl 5):28-31.

55 Al-Hilali N, Al-Humoud H, Ninan VT, Nampoory MR, Puliyclil MA, Johny KV. Does parathyroid hormone affect erythropoietin therapy in dialysis patients? Med Princ Pract. 2007;16(1):63-7.

56 Rao DS, Shih MS, Mohini R. Effect of serum parathyroid hormone and bone marrow fibrosis on the response to erythropoietin in uremia. N Engl J Med. 1993 Jan;328(3):171-5.

57 Chutia H, Ruram AA, Bhattacharyya $\mathrm{H}$, Boruah P, Nath C. Association of secondary hyperparathyroidism with hemoglobin level in patients with chronic kidney disease. J Lab Physicians. 2013 Jan;5(1):51-4.

58 Wang Z, Li J, Wang C, Yao X, Zhao X, Wang $Y$, et al. Gender differences in 1-year clinical characteristics and outcomes after stroke: results from the China National Stroke Registry. PLoS One. 2013;8(2):e56459.

59 Fukuda M, Kanda T, Kamide N, Akutsu T, Sakai F. Gender differences in long-term functional outcome after first-ever ischemic stroke. Intern Med. 2009;48(12):967-73. 